\title{
Optimal dose of methylprednisolone for reduction of propofol injection pain: A randomized, double-blind, placebo controlled study
}

\author{
Dipali Singh ${ }^{1}$, Syed Mudassar ${ }^{2}$, Shivprakash Shivanna ${ }^{3}$, Sathyanarayan $\mathbf{J}^{4}$, Shio Priye ${ }^{5, *}$ \\ ${ }^{\mathbf{1}}$ Associate Professor, ${ }^{\mathbf{2 , 3 , 4}}$ Assistant Professor, ${ }^{\mathbf{5}}$ Professor, Dept. of Anaesthesiology, Vydehi Institute of Medical Sciences \& \\ Research Centre, Karnataka, India \\ *Corresponding Author: \\ Email: shiopriye@gmail.com
}

Received: $14^{\text {th }}$ March, 2018

Accepted: $10^{\text {th }}$ May, 2018

\begin{abstract}
Introduction and Aims: Propofol (2,6-di-isopropylphenol) used for the induction of anaesthesia often causes mild to severe pain on injection, for which various methods have been tried, but with conflicting results. We designed a placebo-controlled, doubleblind study to compare the efficacy of different doses of intravenous methylprednisolone for attenuation of propofol injection pain.

Materials and Methods: One hundred twenty adult patients belonging to the American Society of Anaesthesiologists (ASA) physical Status II and III, between 21 and 60 years, scheduled for elective cardiac surgery, were divided into four groups: saline (group $\mathrm{S}, \mathrm{n}=30$ ), methylprednisolone 40mg (Group methylprednisolone $1 \mathrm{MP} 1, \mathrm{n}=30$ ), methylprednisolone 125mg (group methylprednisolone $2 \mathrm{MP} 2, \mathrm{n}=30$ ) and methylprednisolone 250mg (Group methylprednisolone $3 \mathrm{MP}$, n=30) diluted into 2ml of distilled water. Study drugs were administered after tourniquet application and occlusion was released after 1 min and 1/4th of the total dose of propofol $(2 \mathrm{mg} / \mathrm{kg})$ was administered at the rate of $0.5 \mathrm{ml}$ per second. Pain on propofol injection was assessed by four-point verbal rating scale. Statistical methods used included Chi-square test/Fisher's exact test and Student's $t$-test.

Results: Demographic variables were similar among all the groups. The overall incidence of pain was $70 \%$ in the saline group, $53.33 \%$ in MP1 and $33.33 \%$ in both MP2 \& MP3. Pain intensity was significantly less in patients receiving MP2 \& MP3 drugs for pre-treatment than those receiving saline $(\mathrm{P}<0.05)$. Pre-treatment with MP3 drug itself produced pain with incidence of $16.6 \%$.

Conclusions: Pre-treatment with either $125 \mathrm{mg}$ or $250 \mathrm{mg}$ intravenous methylprednisolone was found to be effective in reducing propofol injection-induced pain. But pre-treatment with $250 \mathrm{mg}$ MP itself was associated with pain during injection.
\end{abstract}

Keywords: Methylprednisolone, Propofol, Pain.

\section{Introduction}

Propofol is an intravenous (IV) anaesthetic drug used for induction and maintenance during anaesthesia. However, its popularity is limited by the adverse effect of pain during intravenous administration. Injection pain is the most common undesired effect of the widely used intravenous anaesthetic agent propofol. Patient satisfaction with perioperative care is assuming more importance in the recent years. The reported incidence of pain with IV propofol varies between $28 \%$ and $90 \%$ in adults. ${ }^{1}$ The quality of pain is described as extremely sharp, aching or burning. Many factors appear to affect the incidence of pain, which include site of injection, size of vein, speed of injection, buffering effect of blood, temperature of propofol and concomitant use of drugs such as local anaesthetics and opiates. ${ }^{2}$

Corticosteroids are systemic anti-inflammatory agents, ${ }^{3}$ systemic analgesics ${ }^{4}$ and are known to block nociceptive $\mathrm{C}$ fibres when applied locally. ${ }^{5}$ Dexamethasone has been shown to reduce propofol injection pain. ${ }^{6}$ Methylprednisolone sodium succinate for injection is available in $40 \mathrm{mg}, 125 \mathrm{mg}, 500 \mathrm{mg}$ and $1000 \mathrm{mg}$ strengths. In a recent study, pretreatment with $125 \mathrm{mg}$ of intravenous MP was found to be as effective as lignocaine in relieving pain during propofol injection. ${ }^{7}$ We therefore designed a comparative study to evaluate the efficacy of intravenous methylprednisolone at different doses in reducing the propofol injection pain.

\section{Materials and Methods}

The study conducted was a comparative, interventional, randomized, prospective, double-blind, parallel group study. The study was conducted in the department of anaesthesiology after obtaining approval from ethical committee of our institute.

In this study, 120 patients between 21 and 60 years irrespective of gender, belonging to the American Society of Anaesthesiologists (ASA) physical Status II and III undergoing elective cardiac surgery were included after obtaining informed written consent. Preoperatively all the patients were continued with antihypertensive drugs. All patients received tablet ranitidine $150 \mathrm{mg}$ and tablet alprazolam $0.5 \mathrm{mg}$ night before the surgery. Patients were divided into four groups of 30 each based on a computer-generated random sequence number.

Exclusion criteria included those patients with difficult venous access, patients with allergy to propofol, patients with cardiac conduction defects, complex congenital heart disease, low ejection fraction, 
diabetes mellitus, chronic pain syndromes, convulsions, head injury and systemic fungal infections.

In the operating room, initial non-invasive monitoring included five lead electrocardiogram and pulse oximetry. A 20-gauge cannula was placed into the largest vein on the dorsum of the left hand. Right radial artery cannulation was performed after local skin infiltration with injection lignocaine under aseptic technique.

The following protocol of study drug was followed in each study group: Group saline (S) patients received $2 \mathrm{ml}$ of normal saline as a placebo; Group methylprednisolone 1 (MP1) patients received methylprednisolone sodium succinate $40 \mathrm{mg}$ diluted into $2 \mathrm{ml}$ of distilled water; Group methylprednisolone2 (MP2) patients received methylprednisolone sodium succinate $125 \mathrm{mg}$ diluted into $2 \mathrm{ml}$ of distilled water, and Group methylprednisolone 3 (MP3) patients received methylprednisolone sodium succinate $250 \mathrm{mg}$ diluted into $2 \mathrm{ml}$ of distilled water. The drugs used in the study were stored at room temperature.

After limb elevation for 15 seconds, a tourniquet was applied around the limb and inflated to $40 \mathrm{mmHg}$ to facilitate venous drainage. As per the study group corresponding drug was injected, and the investigator was blinded to the content of the solution. Tourniquet was deflated after $1 \mathrm{~min}$, and then $0.5 \mathrm{mg} / \mathrm{kg}$ of propofol (long chain triglycerides- LCT) was administered at the rate of $0.5 \mathrm{ml} / \mathrm{second}$. The intensity of pain on injection of propofol was assessed by a second anaesthesiologist who was unaware of the group to which the patient had been allocated. The pain was recorded on a four-point verbal rating scale that was previously described to all the patients. Assessment included standard questions asked to the patients about the comfort of the injection, verbal response and behavioural signs (such as facial grimacing, arm withdrawal or tears from the eyes). Pain was graded using a four-point scale: $0=$ no pain, $1=$ mild pain (pain reported only in response to questioning without any behavioural signs), $2=$ moderate pain (pain reported in response to questioning and accompanied by a behavioural sign or pain reported spontaneously without questioning) and $3=$ severe pain (i.e. strong vocal response or response accompanied by facial grimacing, arm withdrawal or tears).$^{8}$
Further general anaesthesia was continued with IV fentanyl 3-5 $\mu \mathrm{g} / \mathrm{kg}$ and midazolam $0.03 \mu \mathrm{mg} / \mathrm{kg}$. Endotracheal intubation was performed after skeletal muscle relaxation with rocuronium. After securing and confirming tube position, patient was connected to Intermittent positive pressure ventilation and anaesthesia was maintained with isoflurane in air and oxygen mixture. All the haemodynamic parameters including arterial blood pressure and central venous pressure were monitored as per ASA standards. In the post-operative period, all the patients were extubated in the intensive care unit and were assessed for pain, swelling or allergic reaction at the site of injection by an anaesthesiologist who is not aware of the study.

Based on the outcome variable as Pain incidence with minimum difference in any two groups of $20 \%$, thirty patients were calculated as the minimum size for each group assuming $\alpha$-value of 0.05 with a power value of $80 \%$. All measured values are presented as mean \pm standard deviation and numbers $(\%)$. The Statistical software SPSS 15.0 and Microsoft excel was used for the analysis of the data. Analysis of variance (ANOVA) has been used to find the significance of study parameters between three or more groups of patients. Chi-square/ Fisher Exact test has been used to find the significance of study parameters on categorical scale between two or more groups. The statistical significant level of $\mathrm{P}$ value was less than 0.05 .

\section{Results}

There were no significant differences in demographic variables between the four groups [Table 1]. The overall incidence of propofol injection pain was $70 \%$ in the saline group, $53.3 \%$ in the MP1 group, $33.3 \%$ both in MP2 and MP3 [Table 2]. The incidence of pain was significantly less in patients receiving pretreatment with MP2 \& MP3 as compared to saline group $(\mathrm{P} \leq 0.010)$. Severe pain was observed in patients of Groups MP1 (13.3\%), MP2 (3.3\%), and MP3 (3.3\%) respectively as compared to $30 \%$ patients in Saline group ( $\mathrm{P} \leq 0.005$ ). Hence severe pain is significantly more associated with Saline and MP1 group. However, the pre-treatment of study drug methylprednisolone resulted in injection pain in patients of MP2 \& MP3 groups with incidence of $3.3 \%$ and $16.6 \%$ respectively.

Table 1: Demographic data

\begin{tabular}{|l|c|c|c|c|c|}
\hline $\begin{array}{c}\text { Patient } \\
\text { characteristics }\end{array}$ & $\begin{array}{c}\text { Group S } \\
(\mathbf{n = 3 0})\end{array}$ & $\begin{array}{c}\text { Group MP1 } \\
(\mathbf{n = 3 0})\end{array}$ & $\begin{array}{c}\text { Group MP2 } \\
(\mathbf{n = 3 0})\end{array}$ & $\begin{array}{c}\text { Group MP3 } \\
(\mathbf{n = 3 0})\end{array}$ & P value \\
\hline Age (years) & $56.37 \pm 6.01$ & $56.70 \pm 7.08$ & $55.35 \pm 10.29$ & $55.20 \pm 8.45$ & 0.863 \\
\hline Weight(kilograms) & $59.57 \pm 4.58$ & $60.28 \pm 5.98$ & $60.73 \pm 7.58$ & $59.87 \pm 5.57$ & 0.888 \\
\hline Sex (male/female) & $20 / 10$ & $22 / 8$ & $21 / 9$ & $22 / 8$ & 0.931 \\
\hline ASA (II/III) & $9 / 21$ & $9 / 21$ & $8 / 22$ & $7 / 23$ & 0.928 \\
\hline
\end{tabular}

Values are expressed as mean \pm SD or number of patients. $n$ - Number of patients; ASA - American Society of Anesthesiologists; SD - Standard deviation 
Table 2: Incidence and severity of Pain in each group during Propofol injection

\begin{tabular}{|l|c|c|c|c|c|}
\hline $\begin{array}{c}\text { Groups } \\
(\mathbf{n = 3 0})\end{array}$ & No Pain (\%) & Pain (\%) & $\begin{array}{c}\text { Mild Pain } \\
(\mathbf{\%})\end{array}$ & $\begin{array}{c}\text { Moderate } \\
\text { Pain (\%) }\end{array}$ & Severe Pain (\%) \\
\hline Group S & $9(30 \%)$ & $21(70 \%)$ & $6(20 \%)$ & $6(20 \%)$ & $9(30 \%)$ \\
\hline Group MP1 & $14(46.7 \%)$ & $16(53.33 \%)$ & $8(26.7 \%)$ & $4(13.3 \%)$ & $4(13.3 \%)$ \\
\hline Group MP2 & $20(66.7 \%)$ & $10(33.33 \%)$ & $8(26.7 \%)$ & $1(3.3 \%)$ & $1(3.3 \%)$ \\
\hline Group MP3 & $20(66.7 \%)$ & $10(33.33 \%)$ & $7(23.3 \%)$ & $2(6.7 \%)$ & $1(3.3 \%)$ \\
\hline P values & $0.010 * *$ & $0.010 * *$ & 0.919 & 0.196 & $0.005 * *$ \\
\hline
\end{tabular}

Chi-Square test/Fisher Exact test, Data are expressed as number of patients (\%)

Table 3: Pain due to study drugs

\begin{tabular}{|l|c|}
\hline & Pain due study drugs \\
\hline Saline & $0(0 \%)$ \\
\hline Group MP1 & $0(0 \%)$ \\
\hline Group MP2 & $1(3.3 \%)$ \\
\hline Group MP3 & $5(16.66 \%)$ \\
\hline
\end{tabular}

\section{Discussion}

A calm and tranquil anaesthesia induction phase is extremely crucial and of priority in administering general anaesthesia aiming patient comfort and compliance. Unpleasant experiences during induction adversely affect the subsequent stages of anaesthesia. The smooth painless transition of general anesthesia is always favourable and recommended in attenuating adverse hemodynamic response during induction especially in cardiac surgeries. Propofol, which induces rapid and comfortable loss of consciousness, has the significant disadvantage of causing a burning pain. Pain on injection of propofol is a well-recognized entity with a high frequency of $30-80 \% .9,10$

The mechanism for propofol injection pain has been studied widely in the previous literature. The extensive search in the literature suggests that it could be due to irritation of the endothelium, osmolality differences, unphysiological $\mathrm{pH}$ and the activation of pain mediators. ${ }^{11}$ The immediate vascular pain on propofol injection is attributed to direct irritation of the drug $^{12}$ by stimulating the venous nociceptive receptors or free nerve endings involving myelinated $\mathrm{A} \delta$ fibres. ${ }^{13}$ The delayed pain of injection has a latency of 10-20 seconds mediated by activation of kallikrein-kinin system. $^{14}$

There are various strategies to reduce the incidence of pain on injection which includes, pre-treatment with IV lignocaine, adding lignocaine to propofol, ${ }^{15}$ cooling or warming propofol, ${ }^{16}$ injection of propofol into a large vein, ${ }^{17}$ pre-administration of 5 -HT3 receptor antagonist, ${ }^{18}$ dexamethasone, ${ }^{19}$ hydrocortisone ${ }^{20}$ with or without tourniquet. ${ }^{21}$ Among these studies, the most commonly accepted technique is the administration of lignocaine just before the injection of propofol. ${ }^{22}$

A study investigating the optimal dose of lidocaine for the prevention of injection pain due to propofol, found that the addition of $0.1 \mathrm{mg} / \mathrm{kg}$ of lidocaine to 2.5 $\mathrm{mg} / \mathrm{kg}$ of propofol decreased the pain, whereas increasing the dose of lidocaine to 0.2 or $0.4 \mathrm{mg} / \mathrm{kg}$ did not bring additional benefit. ${ }^{23}$ Another study concluded that, the addition of $10 \mathrm{mg}$ of lidocaine to propofol 2 $\mathrm{mg} / \mathrm{kg}$, or the administration of $1 \mathrm{mg} / \mathrm{kg}$ of lidocaine 30 seconds before the administration of propofol $2 \mathrm{mg} / \mathrm{kg}$, effectively decreased pain caused by propofol injection. ${ }^{24}$ The existing database of literature reveals very few studies conducted on corticosteroids as pretreatment for attenuating Propofol injection pain.

Corticosteroids are routinely used in cardiac surgery to attenuate the release of pro-inflammatory cytokines and mitigate the cardiopulmonary bypass effects. The process of nociception consists of four stages; transduction (peripheral nociceptors), transmission (neurons), modulation and pain perception. There is a definitive role of steroids in reducing pain at every stage of nociception but exact mechanism is still unknown. It is suggested that corticosteroids inhibit the production and release of vasoactive and chemo-attractive factors and decreases the secretion of lipolytic and proteolytic enzymes resulting in anti-inflammatory effects. Further it is interesting to note that corticosteroids inhibit the expression of collagenase enzyme involved in tissue degeneration which reduces pro-inflammatory cytokines and also stimulates the synthesis of lipocortin blocking the production of eicosanoids ${ }^{[25]}$. These proinflammatory cytokines synthesized and released during tissue injury are responsible for peripheral sensitization. This process leads to an increase in pain perception. The reduction in inflammation involved in this process decreases nociceptors activation, and thus, can diminish pain intensity. Since one of the proposed mechanisms for pain on propofol injection is mediated through the inflammatory pathway, it was postulated that pretreatment with steroid would attenuate the pain on propofol injection.

As mentioned earlier there is paucity of literature and randomised trials on corticosteroids which can be used to prevent Propofol injection pain. It is worthwhile to quote a study which concluded that the analgesic efficacy of methylprednisolone given as pre-treatment with propofol is as effective as lignocaine in preventing propofol-induced pain. $^{7}$ Another study using dexamethasone in a dose of $0.15 \mathrm{mg} / \mathrm{kg}$ found that $31 \%$ of patients felt pain $(\mathrm{P}<0.01)$ after dexamethasone pretreatment and moderate to severe pain was noticed in $17.14 \% .{ }^{26}$ Based on the previous studies and literature we investigated the most effective and optimal dose of 
methylprednisolone pre-treatment to prevent propofol injection pain. We therefore compared methylprednisolone in the dose of $40 \mathrm{mg}, 125 \mathrm{mg}$ and $250 \mathrm{mg}$ as pre-treatment in preventing the propofol injection pain. It was observed that with pre-treatment of 40mg methylprednisolone, there was significant pain after propofol injection (53.3\%) when compared to pretreatment of 125 and $250 \mathrm{mg}$ methylprednisolone with significant reduction of pain (33.3\%). However, it was observed that pre-treatment with $250 \mathrm{mg}$ of methylprednisolone, produced pain $(16.6 \%)$ in patients of MP3 group. The probable reason could be that $250 \mathrm{mg}$ of methylprednisolone represents a solution of high osmolality and can cause irritation on intravenous injection causing pain.

The limitation of our study is exclusion of pretreatment with higher dose of methylprednisolone fearing its adverse effects and it is practically impossible to constitute in $2 \mathrm{ml}$. There is no postoperative complication observed due to pretreatment of methylprednisolone.

\section{Conclusion}

We conclude that the incidence of pain on injection of propofol is significantly reduced with pre-treatment of methylprednisolone. The optimum dose of methylprednisolone to effectively attenuate propofol injection pain is $125 \mathrm{mg}$. Although at higher doses, methylprednisolone $250 \mathrm{mg}$ is as effective as $125 \mathrm{mg}$ methylprednisolone but higher doses can produce pain.

\section{Conflict of Interest: None}

\section{References}

1. Thukral S, Gupta P, Lakra A, Gupta M. Dexmedetomidine versus ketamine infusion to alleviate propofol injection pain: A prospective randomized and double-blind study. Indian Journal of Anaesthesia. 2015;59:488-92.

2. Jalota L, Kalira V, George E, Shi YY, Hornuss C, Radke $\mathrm{O}$, et al. Prevention of pain on injection of propofol: Systematic review and meta-analysis. BMJ. 2011;342: d1110.

3. Ali-Hassan-Sayegh S, Mirhosseini SJ, Haddad F, KarimiBondarabadi AA, Shahidzadeh A, Weymann A, et al. Protective effects of corticosteroids in coronary artery bypass graft surgery alone or combined with valvular surgery: An updated and comprehensive meta-analysis and systematic review. Interact Cardiovasc Thorac Surg. 2015;20:825-36.

4. Tan PH, Liu K, Peng CH, Yang LC, Lin CR, Lu CY. The effect of dexamethasone on postoperative pain and emesis after intrathecal neostigmine. Anesth Analg. 2001;92:228-32.

5. Johansson A, Hao J, Sjölund B. Local corticosteroid application blocks transmission in normal nociceptive Cfibres. Acta Anaesthesiol Scand. 1990;34:335-8.

6. Kwak KH, Ha J, Kim Y, Jeon Y. Efficacy of combination intravenous lidocaine and dexamethasone on propofol injection pain: A randomized, double-blind, prospective study in adult Korean surgical patients. Clin Ther. 2008;30:1113-9.
7. Shivanna S, Priye S, Singh D, Jagannath S, Mudassar S, Reddy DP. Efficacy of methylprednisolone and lignocaine on propofol injection pain: A randomised, double-blind, prospective study in adult cardiac surgical patients. Indian J Anaesth. 2016;60:848-51.

8. Singh D, Jagannath S, Priye S, Shivaprakash, Kadli C, Reddy D. Prevention of propofol injection pain: Comparison between lidocaine and ramosetron. $J$ Anaesthesiol Clin Pharmacol. 2014;30:213-6.

9. Helbo-Hansen S, Westergaard V, Krogh BL, Svendsen HP. The reduction of pain on injection of propofol: the effect of addition of lignocaine. Acta Anaesthesiologica Scandinavica. 1988;32:502-04.

10. Major E, Verniquet AJW, Waddel TK, Savege TM, Homer DE, Aveling W. A study of three doses of ICI 35868 for induction and maintenance of anaesthesia. British Journal of Anaesthesia. 1981;53:267-72.

11. Ambesh SP, Dubey PK, Sinha PK. Ondansetron pretreatment to alleviate pain on propofol injection: A randomized, controlled, double-blinded study. Anesth Analg. 1999;89:197-9.

12. Tan CH, Onsiong MK. Pain on injection of propofol. Anaesthesia. 1998;53:468-76.

13. Eriksson M, Englesson S, Niklasson F, Hartvig P. Effect of lignocaine and $\mathrm{pH}$ on propofol-induced pain. $\mathrm{Br} \mathrm{J}$ Anaesth. 1997;78:502-6.

14. Nishiyama T. How to decrease pain at rapid injection of propofol: Effectiveness of flurbiprofen. $J$ Anesth. 2005;19:273-6.

15. Walker BJ, Neal JM, Mulroy MF, Humsi JA, Bittner RC, McDonald SB. Lidocaine pre-treatment with tourniquet versus lidocaine-propofol admixture for attenuating propofol injection pain: A randomized controlled trial. Reg Anesth Pain Med. 2011;36:41-5.

16. Ozturk E, Izdes S, Babacan A, Kaya K. Temperature of propofol does not reduce the incidence of injection pain. Anesthesiology. 1998;89:1041.

17. Tariq MA, Kamran M. Incidence of pain on propofol injection and efficacy of addition of lignocaine or selecting big vein or both combined in reducing it: A randomized control trial. J Postgrad Med Inst. 2006;20:811.

18. Sumalatha GB, Dodawad RR, Pandarpurkar S, Jajee PR. A comparative study of attenuation of propofol-induced pain by lignocaine, ondansetron, and ramosetron. Indian $J$ Anaesth. 2016;60:25-9.

19. Gupta M, Mishra S, Gupta D, Gujjar M, Bhatnagar S. Prevention of pain on propofol injection: A comparative, randomized, double blind study between lignocaine, pethidine, dexamethasone and placebo. Internet $J$ Anesthesiol. 2006;11:1-6.

20. Yadav M, Durga P, Gopinath R. Role of hydrocortisone in prevention of pain on propofol injection. $J$ Anaesthesiol Clin Pharmacol. 2011;27:470-4.

21. Kaya S, Turhanoglu S, Karaman H, Ozgün S, Basak N. Lidocaine for prevention of propofol injection-induced pain: A prospective, randomized, double-blind, controlled study of the effect of duration of venous occlusion with a tourniquet in adults. Curr Ther Res Clin Exp. 2008;69:2935.

22. Gharavi M, Sabzevari A, Ghorbanian E, Sajadi R, Akhondi M. Effect of lidocaine volume and concentration on preventing incidence and severity of propofol injection pain. Iran Red Crescent Med J. 2014;16: e16099.

23. Gehan G, Karoubi P, Quinet F. Optimal dose of lignocaine for preventing pain on injection of propofol. Br J Anaesth. 1991;66:324-26. 
24. Halit Madenoglu, Karamehmet Yildiz. Efficacy of Different Doses of Lidocaine in the Prevention of Pain Due to Propofol Injection. Current therapeutic Research. 2003;5:64.

25. Mensah-Nyagan AG, Meyer L, Schaeffer V, Kibaly C, Patte-Mensah C. Evidence for a key role of steroids in the modulation of pain. Psychoneuroendocrinology. 2009; 34 Suppl 1:S169-77.

26. Singh M, Mohta M, Sethi AK, Tyagi A. Efficacy of dexamethasone pre-treatment for alleviation of propofol injection pain. Eur J Anaesthesiol. 2005;22:888-90.

How to cite this article: Singh D, Mudassar S, Shivanna S, Sathyanarayan J, Priye S. Optimal dose of methylprednisolone for reduction of propofol injection pain: A randomized, doubleblind, placebo controlled study. Indian J Clin Anaesth. 2018;5(3):373-377. 